\title{
Alternatives of judicial economic disputes settlement in investment and construction sphere
}

\author{
N Yu Yaskova ${ }^{1}$ \\ ${ }^{1}$ Department of Investment and Construction Business Russian Presidental Academy \\ of National Economy and Public Administration (RANEPA), Prospect Vernadskogo, \\ 84, bldg 2, Moscow, 119571 Russian Federation \\ E-mailmcua3@yandex.ru
}

\begin{abstract}
Modern state of construction industry signifies the necessity of coping with technological backwardness, accrued misbalances, low productiveness of construction business and also its persistent unprofitability and high level of conflict character of construction participants. Actual rise of economic interests contradictions caused by a more complicated character of projects, increase of social burden on construction business induced by inconsistent and even fragmentary measures of public regulation has led to enormous number of economic disputes. Bankruptcy caseload of investment and construction companies is at the highest possible level nowadays. Not only small and middle-sized business but also large companies cannot withstand modern challenges pressure. In this connection there is a huge field for elaboration of dispute resolution methods. Shifting towards project financing strengthens inner contradictions in the industry and also causes conflict of interests with banks. Decline of assets quality, increase of unfinished construction volume, loss of partners, withdrawal of turnover capital, waste of staff, enlargement of shadow economy segment - these are just the part of consequences which should be overcome immediately. Systemic possible solutions deal with the use of the whole specter of disputes resolution methods. Foreign experience, for example Belarusian one, proves that non-judicial methods are more flexible, rational, diverse and acceptable for parties in conflict. The most important thing is that these methods of settling differences have negotiating nature and let the parties find decisions with a high potential of practical fulfillment (not just winning the case in court). Experts expressed different opinions on the issue of conciliation procedure organizational form. The main requirement for arising disputes in investment and construction projects is an uninterrupted process and prevention of bankruptcies: debtors, contractors, subcontractors and construction shareholders. Participants of conference came to the conclusion that certain pilot
\end{abstract}


projects promoting diverse disputes settlement procedures in investment and construction should be launched.

One of the systemic features of modern construction business growth is the snowballing growth of disputes among its participants. Legal actions in their settlement have actually led to the crisis in shared-equity construction. Developers' bankruptcy, growth of the volumes of unfinished construction, hoodwinked investors - all these are just visible aspects of the issue. Shadow sector labour force replenishment, loss of sources of development and economic independence for enterprises in the construction industry, a drop in business activity and a decrease in the volume of commissioned housing still remain out of focus in public discussion. There is a number of reasons for that. First of all, this is an increased influence of uncertainty factors under the conditions of continuous crisis, significant changes in formats and conditions of activity, the complexity of development projects, the ongoing concentration of disproportions and contradictions in investment and construction sphere.

Current situation analyses in settlement of economic disputes in investment and construction sphere has demonstrated:

On the one hand, over past decades, business owners gained much more trust in judicial system and started to delegate the decision-making in disputes to it. It inevitably resulted in overloading the courts with cases and the forced formalism of judicial decisions;

On the other hand, the most intense crisis and call for global transformational processes over the last half of a century were reflected in growth of contradictions in investment and construction sphere participants.

Thirdly, economic interests contradiction enhancement, and sometimes even their polarization, as, e.g. in the field of shared-equity construction, led to the snowballing growth of bankruptcies and reaching the critical limit for business activities in construction.

The way out of existing situation, as the retrospective analysis of judicial practises in the Russian Empire and overseas suggests, can be found in the field of expanding the use of out-of-court methods for economic disputes settlement. Is out-of-court economic disputes settlement possible in Russia in general and in construction sphere in particular? Who and in which way is supposed to institutionalize alternative ways of disputes settlement, including mediation? Which competences will be in demand? The participants of the III International Scientific and Practical Conference "Out-of-court economic disputes settlement in investment and construction sphere" organized by the Department of Investment and Construction Business of the Russian Presidential Academy of National Economy and Public Administration (RANEPA) were trying to find the answers to those questions. For the first time the Academy served as s platform for gathering scientists and practitioners, representing business community interests, major developers and small enterprises, judges, possessing invaluable experience not only in bankruptcy cases, widely covered by media, but also in settlement rooms operating at Moscow City Arbitration Court.

All participants were unanimous, regarding the need for out-of-court methods for disputes settlement in construction. Under the conditions of market crisis and pressure on business, prompt actions of disputes settlement are of great demand than ever, pointed out the presidium member of "OPORA RUSSIA" Pozhidaev Ye.V. "Our experience shows that for small and medium-sized businesses, it is more important to take proactive measures to prevent crisis situations", he said. "The 
issue of economic disputes settlement between large and small construction organizations is no less acute, when courts turn into rigged trials with inevitable bankruptcies of either one, or the other, or both sides".

The representative of the Russian Guild of Property Managers and Developers (GMD) Dykov A.V. described characteristic features of three most common disputes settlement methods. The first, most common is a trial proceeding. Its obvious disadvantage is in overloading the courts with cases that often result in formal nature of judicial decisions that do not include real factors that lead the business to a dangerous line of activity termination. The second alternative mechanism is dispute settlement in arbitration. However, for many reasons, arbitration courts have lost their former popularity and business confidence in them (with the exception of large commercial arbitrations). In any case the dispute brought to court (either commercial arbitration or state) is the last point that can lead to final limit - the bankruptcy. Out-of-court disputes settlement involves the use of alternative methods designed to settle disagreements more quickly and efficiently. Developers' representative opinion was supported by the Associate Professor of the Department of Investment and Construction Business of RANEPA Folomeev Ye.V., who illustrated the critical situation having emerged in medium-size and small business segment by the department's academic research findings [1,2].

Conference moderator, the Head of the Department of Investment and Construction Business of RANEPA Yaskova N.Yu., continuing the analysis of the current situation, noted that, on the one hand, over the past year in Russian judicial system in general proceeded 31 million cases, by the arbitration courts - more than 1 million 900 thousand cases, among which only 1.5\% of the cases ended in settlement agreements. Alongside with that, according to official data execution of the court ruling makes up $50 \%$, but actually it is higher than $30 \%$. That is, the judicial system effectiveness with respect to ensuring constructive cooperation between the parties to the disputes remains low, and most importantly, it adversely affects bona fide participants in entrepreneurial activity, which could have avoided adverse financial consequences, including bankruptcy. On the other hand, Yaskova N.Yu. provided the audience with some examples of finding the way out off the judicial system overloading from the historical perspective [3].

In the real estate sector, the aggregation of controversial issues regarding its mortgage security reached its tremendous scale in the second half of the XIX century. In 1859 the Emperor Alexander II had to issue the decree of the Senate to stop crediting from public credit organizations, thus putting an end to the first wave of mortgage lending. The new rules, symmetrical for both lenders and borrowers, and the suspension of legal proceedings gave Russian real estate the sustainable development nature, and the newly formed banks and societies became launch pads for the accumulation of capital in order to renew and rebuild urban real estate.

At the same time, the focus on the accelerated development of the real estate sector was the main point of legislative amendments. In fact, by the beginning of the 20th century it was completely updated: in central Russia, and in the Caucasus, and in the Baltic, and in the Polish provinces. Thus, in Russia as early as the 19th century, a preventive approach was used to eliminate the collapse of mortgages [4].

In modern conditions, especially in such a highly dynamic industry as construction, contradictions in economic interests and disagreements of participants are inevitable. In fact, all the speakers noted that there is no alternative to the development of efforts at conciliation designed to settle disagreements much more promptly and efficiently, including mediation. The latter present a special type of conciliation efforts, based on third arm's length party participation in the conflict. A mediator 
helps dispute parties have better understanding of their own interests, taking into account further cooperation prospectives, find the way out of the conflict on their own, reach mutually beneficial agreement in the process of dispute settlement and work out solutions, which both party are ready to fulfil.

As the President of the NPO "National Organization for Mediators" Shamlikashvili Ts. A. pointed out, unlike the arbitrator, the mediator does not express his or her opinion on specific methods and prospects for the dispute settlement. He or she also does not decide on the merits, as the arbitrator or judge does. Even in the arbitration court, the parties, in fact, waive the right to independently settle the disagreement, shifting this burden to the arbitrator. Mediation, in turn, gives them the opportunity to maintain control over the content of the agreements and be responsible for decisions taken [5]. That is why more than $85 \%$ of the agreements reached as a result of mediation are voluntarily implemented by the parties.

Another advantage of mediation lies in its confidentiality, as noted the judge of Moscow City Arbitration Court Ageeva L.N. "As an acting judge of the first instance, I can say that disputes in construction activities have the broadest potential for a peaceful settlement. All of the court rulings are subjects to mandatory publication, therefore, conciliation terms will be available to unknown persons. In case of mediation, nobody, including the court, will ever find out what the terms of peaceful settlement have been". Mediator's task is to make sure that the agreement is valid, acceptable for both parties and does not go beyond the framework of the current legislation" [6].

At the same time the Head of the Department of Provision of Proceedings of the Tenth Arbitration Appeal Court Zaitseva L.I. highlighted the fact that it would have been impossible to eliminate the court proceedings as such: the courts' takes, beside everything else, includes judicial practice analysis and generalization, based on which it is possible to establish the specifics of the application of a particular rule of law. At the same time, it is unacceptable to assign to the court those functions that should be implemented by the parties themselves, for example, determining the total cost of work if the parties themselves agreed on a flexible price. Another example is a corporate conflict, in which 5-7 Chief Executive Officers participate and file the opposing claims. Under such conditions ensuring of an adequate and complete dispute settlement is quite complicated for the court [7,8].

The practice of disagreements settlement in an alternative way should be so familiar for legal entities that they will use it automatically. Trying to analyse the courts activity, Ageeva L.N. in a metaphorical way compared it to a surgeon, who will not be asked to amputate the hand in case, for instance, of splinter in the finger. In addition, restrictions have been noted for judges in the framework of the procedural law, in particular, the fact they cannot go beyond the scope of the evidence and the stated requirements. The mediator is that general practitioner, who offers the party to discuss the matter and agree with each other. And only if those attempts cannot bring any positive results, then it is time for court proceedings.

The conference participants also discussed the extremely interesting experience of Moscow City Arbitration Court in organizing the Settlement Room. They first appeared in capital city in 2013 on the initiative of the Chamber of Commerce and Industry of the Russian Federation, supported by Moscow City Arbitration Court. The first agreement was reached the same year. Since that time their popularity has grown ten times. If at the beginning of their operations there were only 90 claims per year, in 2018 this number grew to up to 1,020 .

While holding the discussions, special attention was paid to the experience of foreign states, as well as international organizations. In her speech the arbitrator of the International Commercial Arbitration 
Court at the Chamber of Commerce and Industry of the Russian Federation Gaidaenko Sher N.I. described the activitiesof the International Federation of Consulting Engineers (Federation Internationale des Ingenieurs-Conseils, FIDIC), in the framework of which the relevant provisions on dispute settlement methods have been developed, including in the investment and construction sector. Moreover, in 2017, the FIDIC Yellow Book introduced a special preventive function for Dispute Settlement Councils (commissions) (this is a permanent body being established from the start of the contract), in other words, the prevention of disagreements became their main goal [9]. The arbitrator noted that the International Chamber of Commerce (ICC) also made its provision on specified Councils more modern. The recommendations of such a body may be binding. Moreover, an appeal to the court is possible only after the project the completion, when "the ribbon is cut and all wishes are expressed". Until that moment there is a moratorium in force on disputing all decisions. At the same time ICC can suggest another option - an unbiased specialist who is constantly present at the construction site. A particular uniform is provided for him: a yellow vest and the lettering "mediator" on the back. "If the construction site happens to be in the central part of a small town, and a local resident, irritated by the noise and the dust, files a compliant, a mediator explains him what is going on and offers him an apology. It is enough to settle the disagreement and to release the tension", emphasised Gaidaenko Sher N.I. [10].

To respond to conference moderator's question concerning which country managed to find an optimal combination for court and alternative disputes settlement mechanisms, the international arbitrator came up with an example of Singapore. However, this is explained more by historical, cultural features and mentality, when maintaining a company's reputation is an absolute priority in doing business. And at the same time, market participants respect the state authorities, including the courts. As a result, the Ministry of Justice and judges of the Supreme Court become agents of mediation at the local level and in the courts. In particular, there is an institution of judges who, in the process of considering a dispute, have the right to act as a mediator, thereby helping to settle the dispute and finish the proceedings.

Conference participants also discussed the practise of conciliation efforts within the courts in Switzerland. The procedure provides for the possibility of replacing the conciliator with a mediator in the presence of the interaction difficulties. But the parties are obliged to use at least one of these pretrial procedures. Only in case of the absence of a positive result, "big guns" come in and a court decision is made.

Getting back to the mediation usage in Russia, First Deputy General Director of the Etalon group of companies Viktorov M.Yu. expressed confidence that such an institution has great potential in the light of the ongoing changes in the investment and construction market. According to his data, more than a third of all construction companies are already unprofitable, and the industry is in a state of sharp intensification of all disputes between business entities. And this process will only intensify with the transition of the construction industry to project financing [11]. For instance, on February 1st, 2019, only 700 escrow accounts were opened in 12 Russian banks. The number of applications for project financing from the companies also did not exceed several hundreds. For comparison: in Moscow alone there are more than 800 construction sites, and even more in the Moscow Region. The imperfection of the project financing mechanism and the complexity of the transition to the new development standards, emphasized Yaskova N.Yu., led to a noticeable increase in the number of new arbitration cases on corporate bankruptcies. If in 2016, 7.2 thousand of claims were filed to declare the debtor insolvent; by the end of 2018 this number was twice as much. In $75 \%$ of cases creditors act 
as complainants in companies' bankruptcy. The share of claims from the state increased from $9 \%$ to $15 \%$ (in most cases, the complainant is the tax inspectorate).

Regarding the use of mediation, the results of which could be the conclusion of an amicable agreement in bankruptcy cases, the judge of the Arbitration Court of the Moscow Region Ponomarev D.A. noted that "such procedures are beneficial for participants in shared construction, as they allow to complete the facility, take into account all concerned parties' interests, including the debtor's employees, and pay off the claims in the foreseeable future when monitoring the execution on the creditors' behalf". At the same time, a significant number of persons severely complicate the process of concluding a settlement agreement. For instance, company "SU-155" had 25 thousand of shared construction participants and for Urban Group Company there were 10 thousand. Peaceful settlement in such situations is almost unachievable on the scale of the whole case, but nevertheless it is possible within certain isolated disputes. Such examples are available in the Moscow Region. As part of one of the cases of 2018, a settlement agreement was approved with respect to the construction company, which undertook to complete and obtain commissioning certificate for the residential complex located in the Lyubertsy District of the Moscow Region before May 1st, 2019. In another case (the settlement agreement was approved by the Arbitration Court of the Moscow Region in February 2019), the developer undertook the liability to pay off third-priority claim within 12 months and during the following year - the requirement of the 4th priority claim regarding payment of fines, penalties and forfeits, which were reduced by $20 \%$.

The conference participants noted that within the framework of the disputes settlement alternative methods development, the construction and technical expertise (both out-of-court and legal) did not lose its importance. The Head of the Laboratory for Legal Construction and Technical Expertise of the Russian Federal Center of Legal Expertise under the Ministry of Justice of the Russian Federation Butyrin A.Yu. Shared the information on the latest methodological approach to expertise conducting, also having supported the initiative of experts professional training in out-of-court methods for economic disputes settlement. Doctor of Economics, Prof. Grabovoy K. P. presented his report to the conference participants. The author convincingly proved that the need for better control of each construction stage, starting with examinations of project documentation, stage-by-stage construction control and ending with the accepting of a completed construction project, significantly increased in modern conditions. In this connection construction and technical expertise should form a concept for settlement disputes between participants and if it is possible to settle the dispute out of court, so the independent expert's opinion can clearly demonstrate the prospects for reconciliation. From K.P. Grabovoy's point of view, both legal and alternative ways of settlement are impossible without the application of some particular construction and technical knowledge. It should be combined with procedural knowledge, and educational institutions should jointly begin to train qualified construction experts with the skill to settle disputes.

A certified mediator, a professional negotiator, a mediation and negotiation trainer Ye. E. Kiselev (Saint Petersburg) continued the discussion of the positive experience of out-of-court disputes settlement methods in Russia. He spoke about the initiative on creation M2B (Mediation to Business) team that is the group of mediators, operating in different cities and using the same standards. In particular, there are certain standards for case selection and working with the Commercial Case File. According to the mediator's data, one out of 10 cases is recognized as "mediable"one. Then a mediator finds the parties' contact details and initiates mediation himself/herself. The idea behind this is that neither of the parties finds itself in weaker position in case if it makes a settlement offer. 
Shamlikashvili Ts.A., being a strong supporter for alternative methods non-government status, said: "If we rely on state institutions, we will come to the conclusion that we will create a quasi-state organization that is unlikely to be beneficial. Entrepreneurs should be aware of their own pragmatic interest and responsibility regarding citizens". As an option, the institution for mediators can be created as self-regulatory organization (SRO): "The most important thing is that SRO should actually, but not declaratively, include the tools of alternative disputes settlement in their global landscape. For instance, SROs can make it obligatory for their members to include mediation clauses, that is, to deal with risks using the mediation approach at the very beginning of the project". Representatives of the judicial bodies, based on their own experience, on the contrary, found it necessary to use legislative norms, obliging the parties to use options offered by alternative methods at the pre-trial stage. The opinion of the Department of Investment and Construction Business of RANEPA was less radical. For the integration of out-of-court disputes settlement methods into the real estate sector, and in particular, in construction, not only new standards and rules for conducting investment and construction activities should be developed, but also the industry Centre for out-of-court economic disputes settlement should be created. Its status still has to be determined. The main thing is that it should have the necessary functions, including dispute settlement activities scientific and methodological support, powers ensuring an equal dialogue with the authorities and large developers, as well as resources. "Only systemic activity, integrated into strategic priorities for the development of construction, operating within the mode of taking responsibility for the result under modern conditions is capable of mitigating the situation with court proceedings, if not completely resolving it. The Department's nearest plans for educational activity are the training of specialists with full-fledged management competencies and negotiation skills for resolving contradictions in the investment and construction field" concluded the Head of the Department Yaskova N.Yu.

At the final stage of the Conference, its participants became "debating parties" at a workshop on the negotiation skills development. The active discussions once again convinced the participants of the need to search for forms of alternative methods for economic disputes settlement that would have been adequate to the peculiarities of investment and construction activities.

\section{References}

[1] Yaskova N Yu 2019 Spatial restructuring. New meanings and rules of investment and construction activities ed N Yu Yaskova (Moscow: Publishing House "Delo" RANEPA) p 456

[2] Folomeev Ye V 2013 A process approach to the management of small businesses in construction as a way to increase the efficiency of their activities (University Bulletin vol 5) (Moscow: State University of Management) p 93-99

[3] Yaskova N Yu 2017 Methodological aspects of the cyclicality principle registration in the economic phenomena study of the construction industry (University Bulletin vol 12) (Moscow: Moscow State University of Civil Engineering) No 6 (105) p 680-686

[4] Yaskova N Yu 2019 Non-profit forms of housing construction // Economics and Entrepreneurship No 1 (102) p 899-901

[5] Shamlikashvili Ts A 2017 Mediation is a way to make our world a little better and safer (Moscow: The Bulletin of the Federal Institute of Mediation) No 1 p 10-29

[6] 2015 A.N. Prorokov, L.N. Ageeva and others Small business in Russia: socio-economic, legal and organizational aspects: monograph ed A N Prorokov and L I. Chistokhodova and others 
(Moscow: Information and Publishing Department of Moscow Region State University) p 185

[7] Zaitseva L I 2015 Alternative methods for disputes settlement in the context of interstate relations and economic justice in the Russian Federation (Moscow: Publishing House "Original-Maket") p 216

[8] Zaitseva L I and Yaskova N Yu Application of alternative dispute resolution in the field of construction projects (IOP Conference Series: Earth and Environmental Science) http://iopscience.iop.org/article/10.1088/1755-1315/90/1/012182

[9] Richbell D 2011 Mediation of Construction Disputes (New York: John Wiley \& Sons) p 256

[10] Gaidaenko Sher N I 2018 Agreement forms for disputes settlement arising in connection with business activities (experience of Russia and foreign countries) (Moscow: Publishing House "Yustitsinform") p 398

[11] Viktorov M Yu and Larionov A N 2018 Modern organizational and economic problems of the transition of developers in the Moscow region from shared to project housing construction financing (Moscow: Economics of Construction) No 6 (54) p 12-21 